\title{
Clinical Outcomes Post Implementing Nursing Intervention for Intravenous Immunoglobulin Recipients.
}

\author{
Amna A. Desouky ${ }^{1}$, Mervat A. Abd-El-Aziz ${ }^{2}$ \& Asmaa A. Mahgoub ${ }^{3}$ \\ 1. Assistant Professor of Medical Surgical Nursing, Faculty of Nursing, Assiut University, Egypt. \\ 2. Assistant Professor of Critical Care and Emergency Nursing, Faculty of Nursing, Assiut University, Egypt. \\ ${ }^{3 .}$ Assistant Professor of Critical Care and Emergency Nursing, Faculty of Nursing, Assiut University, Egypt.
}

\begin{abstract}
Background: Immunoglobulin is an effective therapy in Guillain-Barre syndrome patients. Careful monitoring for side effects of immunoglobulin and reduction of complications remains mandatory for nursing care. Aim: To evaluate clinical outcomes post implementing nursing intervention for intravenous immunoglobulin recipient. Hypotheses: A significant reduction in complication incidence and length of hospital stay (ICU - department) among study group than control. Patients and Methods: Design: A quasi-experimental research design. Subjects: A convenience sample of sixty adult patients divided into study and control group diagnosed with Guillian Barre syndrome and had received intravenous immunoglobulin as a line of treatment. Setting: Neurological intensive care unit and department at Assiut University Hospital. Tools: I: patient assessment tool, II: four score assessment tool, and III: patient outcomes assessment tool. The control group subjected to routine hospital nursing intervention while study group received nursing intervention of IVIG administration. Results: Finding revealed a statistical significant decrease in disease complications, IVIG side effect, and hospital stay(ICU- department) in response to implemented nursing intervention between two groups $\mathrm{p}=0.003,0.004$ respectively. Conclusion: Better clinical outcomes had been observed among intravenous immunoglobulin recipient with implemented nursing intervention Recommendation: Nursing intervention should be implemented for all intravenous immunoglobulin recipient to achieve better clinical outcomes.
\end{abstract}

\section{Keywords: Clinical Outcomes, Guillian Barre syndrome, Intravenous immunoglobulin \& Nursing Intervention}

\section{Introduction}

Guillain-Barre syndrome (GBS) is a serious auto immune demyelinating disease in which the body's immune system attacks the myelin sheath of peripheral nervous system-the network of nerves located outside of the brain and spinal cord. Patients with GBS can be presented by manifestations that range from a very mild case with brief weakness to nearly devastating paralysis. Most people reach the greatest stage of devastating paralysis within the first two weeks after symptoms appear. (Dalugama et al., 2018).

In addition to muscle weakness, patients may have others manifestations such as impaired vision and difficulty with eye muscles, unable to swallow, speak, or chew, and needles sensations in the hands and feet, severe pain, particularly at night, coordination problems and unsteadiness, abnormal heart beat/rate or blood pressure, digestion, bladder control problems. These symptoms accelerate in intensity over a period of hours, days, or weeks until certain muscles cannot be contract at all. The attack is life threatening potentially interfering with breathing causing respiratory failure and, sometimes with blood pressure or heart rate abnormalities. (Liu \& May, 2019).
Now two commonly treatments used to interrupt immune-related nerve damage. One is called plasma pheresis or plasma exchange and the other; intravenous immunoglobulin (IVIg). Both treatments have good prognosis for patients with GBS. (Leung et al., 2019). IVIg Injections are developed from a pool of thousands of normal donors. It shorten recovery time when is given to patients within two weeks of symptoms appearance by decreasing the immune attack on the myelin sheath by either "diluting" them with non-specific antibodies or providing antibodies that bind to the harmful antibodies and take them out of action. (Wajih et al., 2018).

Side effect of IVIG can affect many systems: Severe headache, faintness, fever, malaise, dizziness, fatigue are central nervous system side effects. Cardio vascular system affection includes chest pain, chest tightness, heart failure, and myocardial infarction. Digestive system: (diarrhea, abdominal pain, nausea, and vomiting). While musculoskeletal system: (back pain, arthralgia, hip pain, and muscle pain).

Respiratory system: (pulmonary edema, dyspnea, and respiratory distress). Skin: (erythema, urticarial, pain, local infusion-site reactions, rash, and flushing). (Lima et al., 2019). Complications that can occur 
include anaphylaxis, angioedema, chills, respiratory failure, pneumonia, urinary tract infection, and depression. Immobility leads to problems as skin break down, pulmonary embolus, deep venous thrombosis, and muscle atrophy (Kesici et al., 2019 \& Rodríguez et al., 2018).

Nurses have an important role in reduce side effects and complications management; the most important aspect of nursing care during the acute phase is assessment of the patient. Monitor and document the ascending manner of paralysis; assess respiratory rate and pattern; interpret arterial blood gases (ABGs); and examine the gag, corneal, and swallowing reflexes. Proper administration of IVIG therapy. Once IVIG therapy has been initiated, careful infusion monitoring -related reactions is crucial. All side effects should be documented and reported. Maintaining infection control practices and maximizing the patient's nutritional status decrease the likelihood of infection. Muscle strength exercises improve the strength of the weaker muscles and range of motion prevent joint stiffness (Pereira et al., 2020).

\section{Significance of the study}

Guillian Barre syndrome (GBS) occurs throughout the world. The formal documentation of the disease incidence is unknown due to a lack of studies. Although intravenous immunoglobulin as a line of treatment improved the prognosis of Gillian barre patients. The incidence of morbidity and mortality rates remain high. (Umer et al., 2019). With the increase of this syndrome worldwide ,the researchers conducted this study in Neurological Assiut University Hospital assuming that the patients' clinical outcome would improve with the combination of implemented needed nursing intervention in both setting (ICU- department).

\section{Aim of the study:}

To evaluate the clinical outcomes post implementing nursing intervention for Guillian Barre syndrome patients treated with intravenous immunoglobulin.

Operational definitions:

\section{Clinical outcomes:}

It refers to clinical outcomes in the form of complications incidence from Guillian Barre syndrome, side effect of IVIG and length of hospital (ICU - department) stay.

\section{Research hypotheses:}

- A significant reduction in complication incidence for patients who had received nursing intervention less than those who had subjected to routine hospital nursing intervention

- Length of hospital stay (ICU - department) for patients who had received the nursing intervention less than those who had subjected to routine hospital nursing intervention.

\section{Patients and Methods}

Research design:

A quasi-experimental design has been utilized in this study.

Variables:

The implemented nursing intervention is the independent variable in this study. While the dependent variable is the intravenous immunoglobulin recipient clinical outcomes.

Setting:

The study had been carried out in Neurological Hospital (intensive care unit and department) at Assuit University.

\section{Sample:}

A convenience sample of sixty adult patients divided into study and control group (thirty for each) admitted in ICU then transferred to the department at Assiut University Hospital. Patients were selected according to the following criteria: oriented, male and female patients, their age ranges from 18 to 65 years old, diagnosed with poly radiculopathy axonal affection, poly radiculopathy demyelinating affection and mixed axonal and demyelinating Gillian Barre syndrome and had started intravenous immunoglobulin as a line of treatment on admission . Patients who had any other neurologic diseases, musculoskeletal injuries, psychiatric diseases, abnormal kidney function tests, and patients who had co-morbid conditions were excluded.

\section{Tools of the study:}

Three tools had been utilized to gather data pertinent to the study.

Tool (I): Patient assessment sheet:

This tool was developed by the researcher after reviewing of literatures (Pereira et al., 2020; lima et al., 2019 \& Wajih et al., 2018) to assess patient condition; it consisted of three parts:

Part 1: Patients' demographic data:

This part assessed patients' demographic data such as: age, sex, and marital status.

Part 2: Neurological assessment:

This part assessed cranial nerves, which already affected by the disease process.as ocular-motor nerve, trigeminal nerve, facial nerve, vestibulecochlear nerve, glossopharyngeal nerve, and accessory nerves on admission as a base line data.

Part 3: Hemodynamic assessment:

This part assessed temperature, respiration, blood pressure, pulse rate, mean arterial pressure and oxygen saturation. In addition to mechanical ventilator data which includes (mode, tidal volumes, frequency and PEEP). 
Tool II: Four score assessment scale

This scale is a clinical grading scale was adopted (Wijdicks et al., 2005) in this study for assessment of conscious level. It assesses four neurological function domains: eye responses (E), motor responses (M), brainstem reflexes (B), and Respiration (R). It was measured for all patients (control - study) during admission as a base line data, third, and fifth day where patients at intensive care unit and once in the department before discharge from hospital.

\section{Scoring:}

It ranges from zero (0) to sixteen (16), a decreasing in the score means worsening level of consciousness. Scoring was as follow: First: (4) rely on eyelids open or blinking to command in eye response, thumbs -up, fist, or peace sign in motor response, pupillary and corneal reflexes present in brain stem reflex and not intubated, regular breathing pattern in respiration. Second: (3) eyelids open but not tracking in eye response, localizing to pain in motor response, one pupil wide and fixed in brain stem reflex and not intubated, cheyne-stokes breathing pattern in respiration. Third: (2) eyelids closed but open to loud voice in eye response, flexion response to pain in motor response, pupillary or corneal reflexes absent in brain stem reflex and not intubated, irregular breathing pattern in respiration.: (1) eyelids open closed but open to pain in eye response, extension response to pain in motor response, pupillary and corneal reflexes absent in brain stem reflex and intubated, breathes above ventilator rate in respiration. Finally (0) eyelids remain closed with pain in eye response. No response to pain in motor respose. Absent pupillary, corneal, and cough reflex in brain stem reflex and intubated, breathes at ventilator rate or apnea in respiration.

Tool (III): Patient clinical outcomes assessment sheet

This tool was structured by the researcher based on the literature review to evaluate patient's outcomes as complications that raised while patients either in ICU or late in the department as well as side effect of IVIG, and length of hospital stay (ICU - department), this tool was assessed once for all patients (control study).

Operational design: It included

\section{Preparatory phase:}

This phase started by: extensive reviewing of current, past, local and international related literatures as text books, articles, nursing and medical journals.

\section{Content Validity:}

The tools were tested for content related validity by five jury from the following speciality: Critical Care Nursing, Medical Surgical Nursing, and Neurology Medicine from Assiut University who reviewed the tools for clearness, consequence, comprehensiveness, and feasibility for application. Minor adjustments were required. The reliability was $(0.85)$ on study tools by cronback's Alpha.

\section{Pilot Study:}

Six patients was piloted after explaining nature and purpose of study. The purpose of pilot study was two folds: primary; to ensure the clarity of study tools. Secondary; to investigate the utility of the designed tools and identify any obstacles needed to be handled before applying it. Minor modifications was done. Patients involved in the preliminary study omitted from the actual study.

\section{Ethical consideration:}

Formal approval was attained by the researchers from authorities' personnel. At initial interview, patients or their relatives were informed with the aim of study. The researcher stressed that sharing in the study is voluntary and confidentially and privacy will be certain through all the study steps.

\section{Implemented nursing intervention:}

The implemented nursing intervention was established by researchers through reviewing of related literature regarding intravenous immunoglobulin as a line of treatment for ascending Guillian Barre syndrome. The nursing intervention contained two main folds of nursing interventions; first; that is concerned with the role of critical care and emergency researcher, which involved assement of level of consciousness, cranial nerves, and nerve conduction of the extremities nerves, motor weakness and sensory changes. Hemodynamic monitoring which included cardiovascular monitoring (blood pressure, heart rate, dysautonomia manifestations and dysrhythmia). Respiratory monitoring (tidal volume and vital capacity). Swallowing reflex. Monitoring of IVG side effects. In addition to position change to avoid pressure ulcer and maintain proper body alignment, splint placement to prevent wrist hyperflexion, foot board to prevent foot drop. Enteral nutritional support \& care for patients who unable to receive oral feeding. The second fold for medical surgical nursing researcher that continued nursing intervention (inpatient rehabilitation) as hemodynamic monitoring, nasogastric tube care, skin care, breathing and coughing exercises, range of motions for upper and lower extremities, muscle strengthing exercises, in addition to teaching patients how to be independent in their activity of daily living. Experts in fields of nursing and neurology checked the content for comprehensiveness, relevancy and applicability and corrections were done accordingly. 
Implementation phase:

- Data collected from patients who recruited to Neurological Intensive Care Unit (ICU) since Sep.2020 to Feb.2021.

- All patients spent the acute stage of the disease in the ICU then transferred to the department while they were in the recovery stage approximately in the seven ${ }^{\text {th }}$ day since admission.

- At initial interview the researchers introduced herself to initiate line of communication in order to facilitate the implementation of the study.

- Initial assessment was done for all patients (control - study) during admission as a base line data by using tool I ( part 1, 2, and 3) and tool II.

- The control group subjected to usual hospital care while study group received the nursing intervention of IVIG administration.

- The implementation of nursing intervention started from the first day of admission to seven ${ }^{\text {th }}$ day that was implemented by critical care and emergency nursing researcher and one nurse from ICU who was responsible for hemodynamic monitoring of patients as the assignment of duties was functional method.
- Most of patients transferred to the department after the seven ${ }^{\text {th }}$ day since admission where the medical surgical nursing researcher and another nurse from department who were responsible for hemodynamic monitoring of patients too in the department that completed implementation of nursing intervention.

Evaluation phase:

Lastly, all patients were assessed once using tool II and III where the patients in ICU in the fif ${ }^{\text {th }}$ day then assessment had completed before discharge from hospital in third week at the department. As the longterm effect of the disease, all patients went to their home country to continue rehabilitation.

Statistical analysis:

Data were analyzed by using SPSS version 25 (Statistical Package for Social Science). Data had been presented as mean and standard deviation. Chisquare and t-test were used to compare between qualitative variables. P-value considered statistically significant when $\mathrm{P}<0.05$.

\section{Results:}

Table (1): Distribution of the studied patients according to their demographic characteristics. (No=60)

\begin{tabular}{|c|c|c|c|c|c|}
\hline \multirow{2}{*}{$\begin{array}{l}\text { Demographic } \\
\text { characteristics }\end{array}$} & \multicolumn{2}{|c|}{$\begin{array}{c}\text { Control } \\
(n=30)\end{array}$} & \multicolumn{2}{|c|}{$\begin{array}{l}\text { Study } \\
(n=30)\end{array}$} & \multirow[t]{2}{*}{ P-value } \\
\hline & $\mathbf{N}$ & $\%$ & $\mathbf{N}$ & $\%$ & \\
\hline \multicolumn{5}{|l|}{$\overline{\text { Sex }}$} & \multirow{3}{*}{$1.000^{\mathrm{n} . \mathrm{s}}$} \\
\hline Male & 20 & 66.7 & 21 & 70.0 & \\
\hline Female & 10 & 33.3 & 9 & 30.0 & \\
\hline \multicolumn{5}{|l|}{ Age (years) } & \multirow{4}{*}{$0.705^{\mathrm{n} . \mathrm{s}}$} \\
\hline $18----30$ & 8 & 42.1 & 11 & 57.9 & \\
\hline $31-----50$ & 9 & 52.8 & 8 & 47.1 & \\
\hline$>50$ & 13 & 54.2 & 11 & 45.8 & \\
\hline Mean \pm SD & \multicolumn{2}{|c|}{$45.1 \pm 16.65$} & \multicolumn{2}{|c|}{$\frac{1}{40.7 \pm 19.6}$} & $0.357^{\mathrm{n} . \mathrm{s}}$ \\
\hline \multicolumn{5}{|l|}{ Marital status } & \multirow{3}{*}{$0.552^{\mathrm{n} . \mathrm{s}}$} \\
\hline Married & 24 & 80.0 & 21 & 70.0 & \\
\hline Single & 6 & 20.0 & 9 & 30.0 & \\
\hline
\end{tabular}

N.S= no statistical significant difference

Table (2): Distribution of affected cranial nerves among study and control group on admission. $(\mathrm{No}=60)$

\begin{tabular}{|c|c|c|c|c|c|}
\hline \multirow{2}{*}{ Affected cranial nerves } & \multicolumn{2}{|c|}{ Control $(\mathrm{N}=30)$} & \multicolumn{2}{|c|}{ Study $(\mathrm{N}=30)$} & \multirow{2}{*}{ P-value } \\
\hline & $\mathbf{n}$ & $\%$ & $\mathbf{n}$ & $\%$ & \\
\hline \multicolumn{5}{|l|}{ Ocular-motor nerve } & \multirow{3}{*}{$0.004 * *$} \\
\hline Normal & 27 & 90.0 & 30 & 100.0 & \\
\hline Abnormal & 3 & 10.0 & 0 & 0.0 & \\
\hline \multicolumn{5}{|l|}{ Trigeminal nerve } & \multirow{3}{*}{$0.342^{\mathrm{n} . \mathrm{s}}$} \\
\hline Normal & 10 & 33.3 & 11 & 86.7 & \\
\hline Abnormal & 20 & 66.7 & 19 & 13.3 & \\
\hline \multicolumn{5}{|l|}{ Facial nerve: } & \multirow{3}{*}{$0.731^{\mathrm{n} . \mathrm{s}}$} \\
\hline Normal & 26 & 86.7 & 24 & 80.0 & \\
\hline Abnormal & 4 & 13.3 & 6 & 20.0 & \\
\hline
\end{tabular}




\begin{tabular}{|c|c|c|c|c|c|}
\hline \multirow{2}{*}{ Affected cranial nerves } & \multicolumn{2}{|c|}{ Control $(\mathrm{N}=30)$} & \multicolumn{2}{|c|}{ Study $(N=30)$} & \multirow{2}{*}{ P-value } \\
\hline & $\mathbf{n}$ & $\%$ & $\mathbf{n}$ & $\%$ & \\
\hline \multicolumn{5}{|l|}{ Vestibule-cochlear nerve } & \multirow{3}{*}{$0.451^{\mathrm{n} . \mathrm{s}}$} \\
\hline Normal & 15 & 86.7 & 14 & 46.7 & \\
\hline Abnormal & 15 & 13.3 & 16 & 53.3 & \\
\hline \multicolumn{5}{|l|}{ Glossopharyngeal nerve } & \multirow{3}{*}{$0.324^{\mathrm{n} . \mathrm{s}}$} \\
\hline Normal & 21 & 70.0 & 20 & 33.3 & \\
\hline Abnormal & 9 & 30.0 & 10 & 66.7 & \\
\hline \multicolumn{5}{|l|}{ Accessory nerve } & \multirow{3}{*}{$0.005^{* *}$} \\
\hline Normal & 30 & 100.0 & 26 & 86.7 & \\
\hline Abnormal & 0 & 0.0 & 4 & 13.3 & \\
\hline
\end{tabular}

N.S = no statistical significant difference $\quad$ ** highly statistically significant difference $(p<0.05)$

Table (3): Comparison between the study and control groups in relation to hemodynamic items.

\begin{tabular}{|c|c|c|c|}
\hline \multirow[t]{2}{*}{ Hemodynamic items } & $\begin{array}{c}\text { Control } \\
(n=30)\end{array}$ & $\begin{array}{l}\text { Study } \\
(\mathrm{n}=30)\end{array}$ & \multirow[t]{2}{*}{ P-value } \\
\hline & Mean \pm SD & Mean \pm SD & \\
\hline \multicolumn{4}{|l|}{ Heart rate } \\
\hline On admission & $87.97 \pm 11.29$ & $86.27 \pm 9.48$ & $0.831^{\mathrm{n} . \mathrm{s}}$ \\
\hline $3^{\text {rd }}$ day & $87.30 \pm 12.20$ & $90.07 \pm 11.63$ & $0.004 * *$ \\
\hline $5^{\text {th }}$ day & $83.34 \pm 17.20$ & $89.33 \pm 13.06$ & $0.005 * *$ \\
\hline $3^{\text {rd }}$ week (department ) & $87.97 \pm 11.29$ & $91.27 \pm 9.48$ & $0.005^{* *}$ \\
\hline \multicolumn{4}{|l|}{ Respiration } \\
\hline On admission & $21.17 \pm 3.43$ & $21.57 \pm 2.37$ & $0.602^{n \cdot s}$ \\
\hline $3^{\text {rd }}$ day & $22.43 \pm 2.76$ & $23.23 \pm 3.96$ & $0.004 * *$ \\
\hline $5^{\text {th }}$ day & $22.07 \pm 2.86$ & $23.62 \pm 4.24$ & $0.005^{* *}$ \\
\hline $3^{\text {rd }}$ week (department ) & $87.97 \pm 11.29$ & $91.27 \pm 9.48$ & $0.005 * *$ \\
\hline \multicolumn{4}{|l|}{ Mean blood pressure } \\
\hline On admission & $96.8 \pm 11.4$ & $93.1 \pm 12.9$ & $0.246^{\mathrm{ns}}$ \\
\hline $3^{\text {rd }}$ day & $102.8 \pm 11.03$ & $96.8 \pm 13.32$ & $0.004 * *$ \\
\hline $5^{\text {th }}$ day & $109.6 \pm 12.44$ & $95.6 \pm 13.89$ & $0.003 * *$ \\
\hline $3^{\text {rd }}$ week (department ) & $87.97 \pm 11.29$ & $91.27 \pm 9.48$ & $0.005 * *$ \\
\hline \multicolumn{4}{|l|}{ Oxygen saturation } \\
\hline On admission & $94.87 \pm 4.208$ & $93.04 \pm 3.88$ & $0.085^{\text {n.s }}$ \\
\hline $3^{\text {rd }}$ day & $94.53 \pm 4.240$ & $93.23 \pm 3.40$ & $0.195^{\mathrm{ns}}$ \\
\hline $5^{\text {th }}$ day & $93.83 \pm 4.56$ & $94.27 \pm 31.62$ & $0.002 * *$ \\
\hline
\end{tabular}

N.S=no statistical significant difference

** highly statistically significant difference $(p<0.05)$

Table (4): The mean scores of four score assessment between study \& control groups at (ICUdepartment).

\begin{tabular}{|c|c|c|c|}
\hline \multirow[t]{2}{*}{ Four score assessment } & $\begin{array}{c}\text { Control } \\
(\mathrm{n}=30)\end{array}$ & $\begin{array}{l}\begin{array}{l}\text { Study } \\
(\mathrm{n}=30)\end{array} \\
\end{array}$ & \multirow[t]{2}{*}{ P-value } \\
\hline & Mean \pm SD & Mean \pm SD & \\
\hline \multicolumn{4}{|l|}{ Eye response: } \\
\hline On admission & $3.67 \pm 0.661$ & $3.87 \pm 0.571$ & $0.215^{\mathrm{ns}}$ \\
\hline $3^{\text {rd }}$ day & $3.63 \pm 0.669$ & $3.87 \pm 0.571$ & $0.152^{\mathrm{ns}}$ \\
\hline $5^{\text {th }}$ day & $3.67 \pm 0.661$ & $3.87 \pm 0.571$ & $0.015^{*}$ \\
\hline $3^{\text {rd }}$ week (department ) & $3.61 \pm 0.722$ & $3.89 \pm 0.567$ & $0.022^{*}$ \\
\hline \multicolumn{4}{|l|}{ Motor response: } \\
\hline On admission & $3.6 \pm 0.621$ & $3.73 \pm 0.691$ & $0.435^{\mathrm{ns}}$ \\
\hline $3^{\text {rd day }}$ & $3.6 \pm 0.621$ & $3.73 \pm 0.691$ & $0.435^{\mathrm{ns}}$ \\
\hline $5^{\text {th }}$ day & $3.6 \pm 0.621$ & $3.8 \pm 0.63$ & $0.028^{*}$ \\
\hline $3^{\text {rd }}$ week (department ) & $3.57 \pm 0.59$ & $3.79 \pm 0.63$ & $0.023^{*}$ \\
\hline \multicolumn{4}{|l|}{ Brainstem reflexes: } \\
\hline On admission & $3.6 \pm 0.932$ & $3.73 \pm 0.691$ & $0.532^{\mathrm{ns}}$ \\
\hline $3^{\text {rd day }}$ & $3.6 \pm 0.932$ & $3.73 \pm 0.691$ & $0.532^{\mathrm{ns}}$ \\
\hline $5^{\text {th }}$ day & $3.6 \pm 0.932$ & $3.8 \pm 0.61$ & $0.03 *$ \\
\hline $3^{\text {rd }}$ week (department ) & $3.57 \pm 0.992$ & $3.86 \pm 0.525$ & $0.001 * *$ \\
\hline
\end{tabular}




\begin{tabular}{|l|c|c|c|}
\hline \multirow{2}{*}{ Four score assessment } & $\begin{array}{c}\text { Control } \\
(\mathbf{n}=\mathbf{3 0})\end{array}$ & $\begin{array}{c}\text { Study } \\
(\mathbf{n}=\mathbf{3 0})\end{array}$ & \multirow{2}{*}{ P-value } \\
\cline { 2 - 4 } & Mean \pm SD & Mean \pm SD & \\
\hline Respiration: & \multicolumn{3}{|c|}{$0.527^{\mathrm{ns}}$} \\
\hline On admission & $3.03 \pm 1.542$ & $3.27 \pm 1.285$ & $0.005^{* *}$ \\
\hline $3^{\text {rd }}$ day & $3.03 \pm 1.542$ & $3.27 \pm 1.285$ & $0.035^{*}$ \\
\hline $5^{\text {th }}$ day & $3.03 \pm 1.542$ & $3.33 \pm 1.269$ & $0.02^{*}$ \\
\hline $3^{\text {rd }}$ week (department ) & $2.96 \pm 1.522$ & $3.39 \pm 1.227$ & \\
\hline
\end{tabular}

NS=no statistical significant difference

*Statistically significant difference ( $p<0.05)$

Data described as (mean $\pm S D$ ) independent sample t-test

Table (5): Comparison between the study and control groups in relation to developed complications and hospital stay (ICU - department).

\begin{tabular}{|c|c|c|c|c|c|}
\hline \multirow{2}{*}{$\begin{array}{l}\text { Guillain-Barre complications } \\
\text { and IVIG side effects }\end{array}$} & \multicolumn{2}{|c|}{$\begin{array}{c}\text { Control } \\
(\mathrm{N}=30)\end{array}$} & \multicolumn{2}{|c|}{$\begin{array}{c}\text { Study } \\
(\mathrm{N}=30)\end{array}$} & \multirow{2}{*}{ P-value } \\
\hline & $\mathbf{N}$ & $\%$ & $\mathbf{n}$ & $\%$ & \\
\hline \multicolumn{5}{|l|}{ Respiratory } & \multirow{24}{*}{$0.003 * *$} \\
\hline Dyspnea & 4 & 50.0 & 2 & 40.0 & \\
\hline Respiratory distress & 3 & 37.5 & 2 & 40.0 & \\
\hline Pulmonary edema & 1 & 12.5 & 1 & 20.0 & \\
\hline \multicolumn{5}{|l|}{ Cardio vascular } & \\
\hline Chest pain & 4 & 36.4 & 1 & 25.0 & \\
\hline Cardiac dysrhythmia & 3 & 27.3 & 2 & 50.0 & \\
\hline Heart failure & 4 & 36.4 & 1 & 25.0 & \\
\hline \multicolumn{5}{|l|}{ Central nervous } & \\
\hline Fever & 4 & 66.7 & 2 & 28.6 & \\
\hline Dizziness & 3 & 50.1 & 2 & 28.6 & \\
\hline Fatigue & 4 & 66.7 & 2 & 28.6 & \\
\hline Headache & 4 & 66.7 & 1 & 14.3 & \\
\hline \multicolumn{5}{|l|}{ GIT } & \\
\hline Abdominal pain & 4 & 26.7 & 1 & 25.0 & \\
\hline Nausea & 3 & 19.99 & 1 & 25.0 & \\
\hline Diarrhea & 4 & 26.7 & 1 & 25.0 & \\
\hline Vomiting & 4 & 26.7 & 1 & 25.0 & \\
\hline \multicolumn{5}{|l|}{ Musculoskeletal } & \\
\hline Muscle atrophy & 2 & 50.0 & 1 & 50.0 & \\
\hline Joint stiffeness & 2 & 50.0 & 1 & 50.0 & \\
\hline \multicolumn{5}{|l|}{ Skin } & \\
\hline Rash & 4 & 25.0 & 1 & 33.33 & \\
\hline ulcer & 12 & 75.0 & 2 & 66.66 & \\
\hline \multicolumn{5}{|l|}{ Length of hospital stay } & \multirow{3}{*}{$0.004 * *$} \\
\hline ICU stay ( more than 7days) & 5 & 16.66 & 1 & 3.3 & \\
\hline In patient Department stay ( more than 3 weeks) & 25 & 83.33 & 3 & 10.0 & \\
\hline
\end{tabular}

Table (1): Demonestrates that, the highest percentage of both control and study group patients were males $(70.0 \%, 66.7 \%)$ respectively. and their age ranged between 27 and 59 years, with mean \pm SD for control group $40.7 \pm 19$.years as compared to study group $45.1 \pm 16.65$ years.

Table (2): Reflects that; there was no statistical significant difference between control and study groups regarding cranial nerves examination except ocular-motor and accessory nerves.

Table (3): Illustrates hemodynamic assement for studied subjects. It shows that there was no statistically significant difference between control and study groups regarding all parameter of vital signs on admission and all parameters improved on $3^{\text {rd }}, 5^{\text {th }}$ day and in department.

Table (4): Reflects that; there was no statistical significant difference between control and study groups regarding all parameter of four score assessment tool on admission and $3^{\text {rd }}$ day. While on $5^{\text {th }}$ day and in department; there was highly statistical significant difference between the two groups.

Table (5): Demonstrates that; there was highly statistical significant difference between the two 
groups regarding Guillain-Barre complications and IVIG side effects. It was found that; incidence of the complications and IVIG side effects were less among study group than control group. As regard to hospital stay, more patients of control group stayed more days either in ICU or department $(16.66 \%, 83.33 \%$ respectively) as compared to study group (3.3\%, $10.0 \%$ respectively).

\section{Discussion}

Intravenous immunoglobulin (IVIG) is an effective therapy in Guillain-Barre syndrome patients. Careful monitoring for side effects of immunoglobulin and reduction of complications of Guillain-Barre' syndrome remains mandatory for nursing care. The current study found that majority of patients in both groups were males. This study finding agree with a study conducted by Laura et al., 2009 titled in "The epidemiology of Guillain-Barré Syndrome in U.S. military personnel: a case-control study" in which the majority of cases were male $(n=262 ; 83.4 \%)$. Another finding in our study is the majority of the patients in both groups were in age more than fifty years this is contrary to age of cases group in the same study in which the majority of cases were between the ages of 20 and 24 years. However Kohrmann et al., 2009 conducted a study titled in " Incidence of Guillain-Barré syndrome at a secondary center during the 2016 zika outbreak". Which revealed that the most affected age group was 50-59 years.

As regard to hemodynamic parameters, the present results showed there was no statistical significant difference between control and study groups regarding hemodynamic parameters on admission. This finding may represent the true scientific nature of the disease as the affection of peripheral nerves lead to impairment \& limitations of many body functions. While on $3^{\text {rd }}, 5^{\text {th }}$ day and in department; a statistical significant difference between study and control groups had been observed. This could be explained; improvement may be attributable to the implemented nursing intervention and continuous monitoring of these simple bedside parameters which should continue until clear and constant improvement in patients' condition is detected. In contrast to our results Kohrmann et al., 2009 found frequent poor clinical outcome in Guillain-barre' syndrome (GBS) patients who were treated in an Intensive Care Unit (ICU) during the disease acute phase as well as long- term mortality rate of $20 \%$ at 12 months or longer after hospital discharge .

As regard to neurological examination; at presentation and third day; there was no statistical significant difference between control and study groups regarding all parameters of four score assessment tool. As mentioned before; this finding also may represent the true scientific nature of the disease as the affection of peripheral nerves leads to impairment \& limitations of many body functions. While on $5^{\text {th }}$ day and in department; there was highly statistical significant changes between the two groups as the improvement was higher in study group than control group. This result is parallel to Boostani et al., 2019 who carried a study titled in "A follow-up study on Guillain Barre syndrome and validation of bright on criteria" mentioned that at initial presentation, only $6.8 \%$ of patients were able to walk. This percent enlarged to $52.7 \%$ of patients by one month later.

As regard to systemic complications and IVIG side effects; the current results showed that; Incidence of the systemic complications and IVIG side effects were less among study group than control group during different times of assessment, In the researchers' point of view this could be attributed to the effect of implemented nursing intervention during inpatient rehabilitation. In the same line a study conducted by Novak et al., 2017 titeled in " Rehabilitation of Guillain-Barré syndrome patients: an observational study" with sample size forty -five who found that; clinically important and statistically significant progresses in all outcome measures (body functions and activities) among studied patients after they had completed inpatient rehabilitation.

Others Hughes \& Cornblath, 2016; Yuki and Hartung, 2012 reported that; many patients were relatively having good clinical outcome. However, in some patients, impairments of diverse body functions with subsequent activity and participation limitations remains up to 6 months and more, twenty percent of the patients having difficulty in walking. Bernsen et al., $2002 \&$ Bersano et al., 2006 added that pain and fatigue persist for several years in many patients. And suggested that; almost one-third of GBS patients must change their life style or other activities because of diseases.

As regard to hospital length of stay, high number of control group patients stayed more days either in ICU or department as compared to study group. This long period of hospital length of stay among control group patient may be a consequence of poor clinical outcome, which they have had versus short length of stay among study group. This finding was supported by Shangab \& Al Kaylani, 2020 who conducted a study titled in "Clinical course and predictors of poor functional outcome in Guillain-Barre Syndrome. A Retrospective Study" found that longer duration of hospital stay among patients who had poor functional outcomes \& morbidity as compared to patients with good functional outcomes. 
Conclusion:

Finally, in the fact, this study documented that; implementation of nursing intervention for GuillainBarre syndrome patients who receiving intravenous immunoglobulin therapy produced better clinical outcomes (decreased complications, side effects, and length of hospital stay).

\section{Recommendation:}

- Combined Nursing intervention (ICU- department) should be implement for all GuillainBarre syndrome patients who receiving intravenous immunoglobulin to achieve better clinical outcomes.

- Periodical assessment of patients' progress is needed to ensure optimal patient outcome.

- Future studies with large sample should be replicated for Guillain-Barre syndrome patients from diverse geographic areas to generalize the results.

\section{References:}

- Bernsen RA, de Jager AE, Schmitz PI, van der \& Meche FG (2002): Long-term impact on work and private life after Guillain-Barré syndrome. J Neurol Sci 201:13-17.

- Bersano A, Carpo M, Allaria S, Franciotta D, Citterio A, \& Nobile-Orazio E (2006): Long term disability and social status change after GuillainBarré syndrome. J Neurol 253:214-218.

- Boostani R, Ramezanzadeh F, Saeidi M, \& Khodabandeh M.; (2019): A follow-up study on GuillainBarre syndrome and validation of brighton criteria. Iran J Neurol. 2019 Apr 4;18(2):64-9

- Dalugama C, Shelton J, Ekanayake M, \& Gawarammana IB; (2018): Dengue fever complicated with Guillain-Barré syndrome: a case report and review of the literature. J Med Case Rep 12(1): 137.

- Hughes RAC, \& Cornblath DR; (2016): Willison HJ Guillain-Barré syndrome in the 100 years since its description by Guillain, Barré and Strohl. Brain; 139:3041-47.

- Kesici S, Tanyıldız M, Yetimakman F, \& Bayrakci B; (2019): A Novel Treatment Strategy for Severe Guillain-Barré Syndrome: Zipper Method. J Child Neurol (5): 277-283.

- Kohrmann M, Huttner HB, Nowe T, Schellinger PD, \& Schwab S; (2009): Mechanical ventilation in Guillain-Barre' syndrome: does age influence functional outcome? Eur Neurol 61:358-363

- Laura N, Robert G, Mark S, David R 3 \& Chad K; (2009): The epidemiology of Guillain-Barré Syndrome in U.S. military personnel: a casecontrol study, BMC Research Notes;P.P.1-7; available at: http://www.biomedcentral.com/17560500/2/171

- Leung J, Sejvar JJ, Soares J, \& Lanzieri TM; (2019): Guillain-Barré syndromeand antecedent cytomegalovirus infection,. Neurol Sci: Apr;41(4):885-891. doi: 10.1007/s10072-01904156.

- Lima MES, Bachur TPR, \& Aragão GF; (2019): Guillain-Barre syndrome and its correlation with dengue, Zika and chikungunya viruses infection based on a literature review of reported cases in Brazil. Acta Trop 197: 105064

- Liu H, \& MaY (2019): Hepatitis E virusassociated Guillain-Barre syndrome: Revision of the literature. Brain Behav 11: e01496.

- Novaka Primož, Šmida Sonja \& Vidmar Gaj;(2017): Rehabilitation of Guillain-Barré syndrome patients: an observational study, Wolters Kluwer Health,158:163 p.p. DOI: 10.1097/MRR.0000000000000225

- Pereira T, Pâmela Beatriz do Rosário Estevam dos Santos, Vivian Cristina Costa Castilho Hyodo. (2020): Recent Advances in Studies on Guillain-Barre Syndrome: Correlation Between Microorganisms and New Treatment Perspectives. Biomed J Sci \& Tech Res 24(3)-2020. BJSTR. MS.ID.004040.

- Rodríguez Y, Rojas M, Pacheco Y, AcostaAmpudia Y, \& Ramírez-Santana C, (2018): Guillain-Barré syndrome, transverse myelitis and infectious diseases. Cell Mol Immunol 15(6): 547562.

- Shangab M. \& Al Kaylani M.; (2020): Clinical Course and Predictors of Poor Functional Outcome in Guillain-Barré Syndrome. A Retrospective Study, Dubai Med J 2020;3:93-98DOI: 10.1159/000510443

- Umer S, Nisa Q, Kumari M, Abbas S, Mahesar S, Shahbaz N. Neurology, Dow University of Health Sciences, Karachi, PAK \& Neurology, Civil Hos. (2019): Clinical Features Indicating the Need for Mechanical Ventilation in Patients with Guillain Barre Syndrome. Cureus 11(8): e5520. DOI 10.7759/cureus.5520

- Wajih Ullah M, Qaseem A, \& Amray A (2018): Post Vaccination Guillain Barre Syndrome: A Case Report. Cureus 10(4): e2511.

- Wijdicks EF, Bamlet WR, Maramattom BV, Manno EM, \& McClelland RL (2005): "Validation of a new coma scale: The FOUR score". Annals of Neurology. 58 (4): 58593. doi:10.1002/ana.20611. PMID 16178024

- Yuki N, \& Hartung HP; (2012): Guillain-Barré syndrome. N Engl J Med. 366:2294-304. 